\title{
ENUMERAÇÃO DE MICRORGANISMOS CAUSADORES DA MASTITE BOVINA E ESTUDO DA AÇÃO DE ANTIMICROBIANOS
}

\section{Counts of microorganisms causing bovine mastitis and study of antimicrobial action}

\author{
Wanessa Oliveira Ribeiro ${ }^{l}$, Renata Leortina de Oliveira ${ }^{l}$, Maurilio Lopes Martins ${ }^{1 *}$, \\ José Manoel Martins ${ }^{l}$, Angelo Herbet Moreira Arcanjo ${ }^{I}$, Onofre Barroca de Almeida Netol
}

\section{RESUMO}

A mastite é uma inflamação da glândula mamária causada, principalmente, por microrganismos, que altera as características do leite e acarreta prejuízos econômicos significativos para esta cadeia produtiva. O trabalho teve como objetivo determinar os principais agentes causadores de mastite no rebanho leiteiro de uma propriedade do município de Rio Pomba, MG, e avaliar o uso de extrato de aroeira e de antibióticos comumente utilizados no controle dos microrganismos causadores desta enfermidade. Amostras de leite cru procedentes de 47 bovinos em lactação foram coletadas individualmente para avaliação microbiológica. Também foi avaliada a sensibilidade dos isolados obtidos ao extrato de aroeira e a antibióticos comumente utilizados na propriedade. Constatou-se que 17,0\%, 31,9\%, $85,4 \%$ e $38,3 \%$, das amostras apresentaram, respectivamente, Staphylococcus aureus, coliformes totais, coliformes fecais e Escherichia coli. Além disso, a maioria das amostras apresentou contagens de microrganismos mesófilos aeróbios e Streptococcus sp. entre $10^{4}$ e $10^{5}$ UFC. $\mathrm{mL}^{-1}$, enquanto as contagens de $S$. aureus variou entre $10^{2}$ e $10^{3}$ UFC. $\mathrm{mL}^{-1}$ na maioria das mesmas amostras. Verificouse maior eficácia de tetraciclina sobre os isolados de $S$. aureus e de ampicilina sobre os isolados de E. coli. Todos os isolados dessa última bactéria foram resistentes ao extrato de aroeira. Devido à elevada incidência de microrganismos

1 Instituto Federal de Educação, Ciência e Tecnologia do Sudeste de Minas Gerais, Campus Rio Pomba. Departamento de Ciência e Tecnologia de Alimentos, Avenida Dr. José Sebastião da Paixão, s/n, Bairro Lindo Vale, Caixa Postal 45, 36180-000, Rio Pomba, MG, Brasil. E-mail: maurilio.martins@ ifsudestemg.edu.br

* Autor para correspondência

Recebido / Received: 22/04/2013

Aprovado / Approved: 18/10/2013 
ressalta-se a necessidade de implantação das Boas Práticas Agropecuárias na produção de leite, pois essas bactérias são procedentes do pelo, pele, mucosas dos animais e/ou pertencentes à microbiota entérica de mamíferos, respectivamente. Palavras-chave: infecção; mastite; patógenos; leite cru.

\begin{abstract}
Mastitis is an inflammation of the mammary gland caused mainly by microorganisms, altering the characteristics of milk and results in significant economic losses for this production complex. The study aimed to determine the main causative agents of bovine mastitis in a dairy farm in Rio Pomba city, Minas Gerais state, Brazil, and evaluate the use of plant extract and antibiotics commonly used in the control of microorganisms that cause this disease. Raw milk samples coming from 47 dairy cow were individually collected for microbiological evaluation. We also evaluated the sensitivity of isolates from the plant extract and the antibiotics commonly used in the farm. It was found that 17.0 $\%, 31.9 \%, 85.4 \%$ and $38.3 \%$ of the samples presented, respectively, Staphylococcus aureus, coliforms, faecal coliforms and Escherichia coli. Furthermore, most of the samples showed counts of aerobic mesophilic microorganisms and Streptococcus sp. between $10^{4}$ and $10^{5}$ CFU.mL $L^{-1}$, while the counts of $S$. aureus ranged between $10^{2}$ and $10^{3}$ CFU.mL $\mathrm{mL}^{-1}$ in most of samples. A higher efficacy of tetracycline on the isolates of $S$. aureus was verified and of ampicillin on the E. coli isolates. All isolates of the latter bacteria were resistant to plant extract. Due to the high incidence of microorganisms, we emphasize the need for implementation of Good Agricultural Practices in milk production, because these bacteria are coming from hair, skin, mucous membranes of animals and/ or belonging to the enteric microbiota of mammals, respectively.
\end{abstract}

Keywords: infection; mastitis; pathogens; raw milk.

\section{INTRODUÇÃO}

A mastite bovina é uma doença de grande importância na pecuária leiteira, que ocasiona a inflamação da glândula mamária, sendo responsável por perdas econômicas significativas. A presença da mastite significa para o produtor um menor retorno econômico, devido à redução na produção, aos gastos com medicamentos e também com as penalidades aplicadas pelos laticínios. Além desses prejuízos, esta enfermidade representa um risco à saúde do consumidor (CASSOL et al., 2010). S. aureus encontra-se entre os principais agentes causadores das mastites contagiosas em vacas leiteiras, uma vez que apresenta alta prevalência em rebanhos de todo o mundo (SANTOS, 2012).

Entretanto, um dos grandes desafios no desenvolvimento de novas medidas terapêuticas para prevenção da mastite é a limitada disponibilidade de drogas (NÓBREGA et al., 2009). Segundo Cassol et al., (2010) com o progresso tecnológico na área da farmacologia antimicrobiana, alguns problemas foram surgindo, dentre eles, o uso inadequado de drogas no intuito de sanar doenças bacterianas que atacam o rebanho leiteiro. Este fato resultou em respostas dos principais agentes etiológicos de mastite, conduzindo à seleção de bactérias resistentes.

Um dos fitoterápicos mais utilizados na 
formulação de antimicrobianos é o extrato de aroeira (Schinus terebinthifolius raddi). Segundo Silva et al., (2010) esse composto apresenta potencial para tratamento de mastite bovina, uma vez que foi o mais efetivo dos extratos naturais testados contra $S$. aureus isolados de leite cru da região de Rio Pomba, MG. Entretanto, são necessários maiores estudos sobre a forma de aplicação e modo de ação desse extrato.

A utilização de um conjunto de medidas preventivas e curativas é necessária, principalmente, no que diz respeito à busca por novos antimicrobianos, destacando-se os produtos naturais potencialmente capazes de solucionar o problema da resistência aos antimicrobianos colocados à disposição atualmente (PEREIRA et al., 2010).

Desta forma, este trabalho objetivou determinar os principais agentes causadores de mastite bovina no rebanho leiteiro de uma propriedade do município de Rio Pomba, MG, e avaliar o uso de extrato de aroeira e de antibióticos utilizados rotineiramente na propriedade leiteira contra os microrganismos causadores desta enfermidade.

\section{MATERIAL E MÉTODOS}

\section{Coleta de amostras}

Amostras de $200 \mathrm{~mL}$ de leite cru foram coletadas assepticamente em frascos de vidro esterilizados de cada bovino em lactação de uma unidade produtora de leite do município de Rio Pomba, totalizando 47 amostras durante os meses de setembro de 2011 a fevereiro de 2012. Imediatamente após a coleta, as amostras foram refrigeradas e encaminhadas para o Laboratório de Microbiologia de Alimentos do Departamento de Ciência e Tecnologia de Alimentos do Instituto Federal de Educação, Ciência e Tecnologia do Sudeste de Minas Gerais (IF Sudeste MG), Campus Rio Pomba para análises.

\section{Avaliação Microbiológica}

A contagem de microrganismos mesófilos aeróbios, estafilococos e estafilococos coagulase positiva em leite cru foi realizada de acordo com o preconizado na Instrução Normativa n. ${ }^{\circ} 62$ (BRASIL, 2003). Desta forma, utilizou-se ágar padrão para contagem - PCA (ISOFAR) para a enumeração de microrganismos mesófilos aeróbios, ágar Baird-Parker (ISOFAR) adicionado de telurito de potássio e gema de ovo para a enumeração de estafilococos e estafilococos coagulase positiva. A enumeração de Streptococcus sp. foi realizada segundo Downes; Ito (2001) utilizando o meio azida agar base sangue (HIMEDIA). O Número Mais Provável (NMP) de coliformes foi determinado utilizando-se Caldo Lauril Sulfato Triptose - LST (HIMEDIA) no teste presuntivo, seguido de confirmação de coliformes totais em caldo verde brilhante - VB (HIMEDIA) e de coliformes termotolerantes em caldo Escherichia coli - EC (HIMEDIA) (BRASIL, 2003). A enumeração de $E$. coli foi realizada de acordo com Kornacki; Johnson (2001).

\section{Caracterização e estocagem dos isolados}

Para o isolamento das culturas de estafilococos coagulase positiva foram selecionadas, das maiores diluições, três colônias negras, pequenas, rodeadas por uma zona opaca e/ou um halo transparente devido à ação das enzimas lecitinase e protease no meio de cultura ágar Baird-Parker (ISOFAR). Os isolados selecionados foram ativados e caracterizados quanto à morfologia, atividades de coagulase, termonuclease, catalase e reação de Gram (BRASIL, 2003). Aqueles microrganismos que apresentaram características típicas de $S$. aureus foram ativados e congelados a $-20{ }^{\circ} \mathrm{C}$ em caldo infusão de cérebro e coração - BHI (HIMEDIA), adicionado de $20 \%$ de glicerol a fim de se iniciar uma coleção de cultura deste microorganismo. 
O isolamento de E. coli foi realizado a partir das colônias típicas em meio eosina azul de metileno (HIMEDIA). A identificação desta bactéria foi realizada por meio de provas bioquímicas de rotina (INViC) (KORNACKI; JOHNSON, 2001). Aqueles microrganismos que apresentaram características típicas de E. coli foram ativados e congelados a $-20^{\circ} \mathrm{C}$ em caldo infusão de cérebro e coração - BHI (HIMEDIA), adicionado de $20 \%$ de glicerol a fim de se estabelecer a coleção de cultura desta bactéria.

\section{Avaliação da sensibilidade dos isolados a antibióticos de uso no controle da mastite bovina}

Os isolados da coleção de cultura foram ativados em caldo Infusão de Cérebro e Coração - BHI (HIMEDIA) a $37^{\circ} \mathrm{C}$ até que atingisse densidade óptica 0,5 medida em espectrofotômetro com comprimento de onda de $600 \mathrm{~nm}$. Posteriormente, as culturas foram transferidas com auxílio de $s w a b$ estéril para placas de Petri contendo Ágar MuellerHinton (HIMEDIA), sendo estas divididas em quadrantes. Com o auxílio de uma pinça previamente flambada, os discos de papel contendo concentrações conhecidas dos antibióticos ampicilina $(10 \mu \mathrm{g})$, tetraciclina (30 $\mu \mathrm{g})$ e ácido nalidíxico $(30 \mu \mathrm{g})$ foram transferidos assepticamente para a superfície do meio de cultura inoculado com o microrganismo. Posteriormente, as placas foram incubadas por 16 a 18 horas a $37^{\circ} \mathrm{C}$ e o crescimento bacteriano nas placas avaliado, procurando identificar as zonas de inibição em torno dos discos de papel. O diâmetro ( $\mathrm{mm}$ ) da zona de inibição foi medido com régua milimetrada e os resultados foram comparados com os valores de referência da Sociedade Brasileira de Microbiologia (BORGES et al., 2004).

\section{Elaboração do extrato de aroeira-da-praia}

A casca de aroeira-da-praia foi coletada pela manhã no Campus Rio Pomba do IF Sudeste MG e triturada de modo a se obter $25 \mathrm{~g}$ de material, que, posteriormente, foi tratado com $100 \mathrm{~mL}$ de etanol $70 \%$ para a dissolução do extrato permanecendo em repouso por 15 dias sob abrigo da luz. Diariamente, o extrato foi homogeneizado. Posteriormente, o material foi filtrado por duas vezes à temperatura ambiente com auxílio de bomba de vácuo para eliminação dos sólidos. $\mathrm{O}$ extrato bruto foi concentrado em evaporador rotativo a $40^{\circ} \mathrm{C}$ e esterilizado pelo método de filtração com o auxílio de membrana filtrante de $0,22 \mu \mathrm{m}$ (Millipore). O filtrado foi coletado e acondicionado em recipientes escuros esterilizados e mantidos a $4,0{ }^{\circ} \mathrm{C}$ (COSTA, 2010).

\section{Avaliação do efeito antimicrobiano de extrato de aroeira sobre os isolados}

A avaliação da atividade do extrato de aroeira sobre os microrganismos ( $E$. coli e $S$. aureus) da coleção de cultura foi realizada de acordo com as recomendações da National Committee for Clinical Laboratory Standards (NCCLS, 2005). Os microorganismos foram semeados em caldo BHI e incubados a $37{ }^{\circ} \mathrm{C}$ por $24 \mathrm{~h}$. Posteriormente, os inóculos foram padronizados de acordo com a solução padrão de McFarland 0,5 a um comprimento de onda de $625 \mathrm{~nm}$ de modo a se obter, aproximadamente, $10^{8}$ células. $\mathrm{mL}$ 1. Em seguida, foi preparado ágar Mueller Hinton, o qual foi distribuído em placas de Petri de $56 \mathrm{~mm}$ de diâmetro, com volume suficiente para atingir a espessura de $4 \mathrm{~mm}$ de profundidade. Após a solidificação, por meio da técnica de semeadura em superfície, as suspensões microbianas foram inoculadas esfregando-se o $s w a b$ em toda a superfície do ágar. $\mathrm{O}$ procedimento foi repetido mais duas vezes, em diferentes sentidos, a fim de assegurar a distribuição uniforme do inóculo. Posteriormente, as placas foram mantidas semiabertas em fluxo laminar por 5 minutos 
para a remoção do excesso de umidade. Em seguida, pocinhos com $0,5 \mathrm{~cm}$ de diâmetro foram feitos no ágar com auxilio de ponteira estéril, sendo então adicionados $25 \mu \mathrm{L}$ do extrato bruto de aroeira por pocinho. Após a difusão do extrato, as placas inoculadas foram incubadas invertidas em estufas a 36 ${ }^{\circ} \mathrm{C}$ por um período de 16 a 18 horas. Após a incubação a atividade antimicrobiana foi avaliada pela medida do diâmetro do halo de inibição do crescimento do isolado em torno dos pocinhos. Halos com diâmetro igual ou superior a $10 \mathrm{~mm}$ foram considerados indicativos de sensibilidade do isolado ao extrato.

\section{RESULTADOS E DISCUSSÃO}

Constatou-se que a maioria das amostras de leite cru apresentou contagens elevadas dos microrganismos avaliados (Tabelas 1 e 2).
Verificou-se que $81,0 \%, 48,6 \%, 59,6 \%$ e $56,4 \%$ apresentaram contagens de mesófilos aeróbios, estafilococos presuntivo, estafilococos coagulase positiva e Streptococcus sp., respectivamente, em uma faixa de $10^{2}$ a $10^{5}$ UFC. $\mathrm{mL}^{-1}$.

A elevada incidência de bactérias do grupo coliformes nas amostras evidencia a carência de adoção das Boas Práticas Agropecuárias na produção de leite do rebanho avaliado (Tabela 2). Além disso, a partir dos resultados de identificação constatou-se presença de $S$. aureus (Gram-positivos, coagulase, catalase e termonuclease positivos) e E. coli em $17,0 \%$ e $38,3 \%$ das amostras, respectivamente. A confirmação de E. coli evidencia necessidade de implementação das boas práticas higiênico sanitárias na produção leiteira, uma vez que este microrganismo é de origem entérica. A elevada presença de S. aureus indica a possibilidade de alguns

Tabela 1 - Contagem de microrganismos das amostras de leite cru dos bovinos em lactação

\begin{tabular}{ccccr}
\hline $\begin{array}{l}\text { Faixas de contagens } \\
\left(\mathrm{UFC} . \mathrm{mL}^{-1}\right)\end{array}$ & Mesófilos aeróbios & Estafilococos presuntivo & S. aureus & Streptococcus sp. \\
\hline$<1,0 \times 10^{1}$ & $2,13 \%$ & $0,00 \%$ & $12,77 \%$ & $7,69 \%$ \\
$1,0 \times 10^{1}$ a $1,0 \times 10^{2}$ & $10,64 \%$ & $10,64 \%$ & $21,28 \%$ & $12,82 \%$ \\
$1,1 \times 10^{2}$ a $1,0 \times 10^{3}$ & $23,40 \%$ & $17,02 \%$ & $29,79 \%$ & $17,95 \%$ \\
$1,1 \times 10^{3}$ a $1,0 \times 10^{4}$ & $27,66 \%$ & $19,15 \%$ & $27,65 \%$ & $12,82 \%$ \\
$1,1 \times 10^{4}$ a $1,0 \times 10^{5}$ & $29,79 \%$ & $12,77 \%$ & $2,13 \%$ & $25,64 \%$ \\
$1,1 \times 10^{5}$ a $1,0 \times 10^{6}$ & $4,25 \%$ & $19,15 \%$ & $0,00 \%$ & $5,13 \%$ \\
$1,1 \times 10^{6}$ a $1,0 \times 10^{7}$ & $2,13 \%$ & $14,89 \%$ & $0,00 \%$ & $10,26 \%$ \\
$1,1 \times 10^{7}$ a $1,0 \times 10^{8}$ & $0,00 \%$ & $4,25 \%$ & $4,25 \%$ & $5,13 \%$ \\
$>1,0 \times 10^{8}$ & $0,00 \%$ & $2,13 \%$ & $2,13 \%$ & $2,56 \%$ \\
\hline
\end{tabular}

Tabela 2 - Número Mais Provável (NMP) de coliformes nas amostras de leite cru dos bovinos em lactação

\begin{tabular}{ccc}
\hline NMP.mL & Coliformes totais & Coliformes termotolerantes \\
\hline$<0,03$ & $14,9 \%$ & $14,9 \%$ \\
0,03 a 3 & $42,6 \%$ & $57,4 \%$ \\
4 a 11 & $10,6 \%$ & $4,3 \%$ \\
$>11,0$ & $31,9 \%$ & $23,4 \%$ \\
\hline
\end{tabular}


animais serem portadores de mastite, tornando os animais sadios aptos a uma possível contaminação por esta bactéria.

De acordo com Martins el al., (2010) $S$. aureus é um dos agentes causais mais prevalentes nas manifestações subclínicas da mastite. Dentre os casos de mastite clínica, os autores também relataram alta frequência de $S$. aureus $(44,0 \%)$ e de Corynebacterium sp. $(12,0 \%)$. De acordo com os resultados de Guimarães et al. (2012) ao analisarem leite mastítico, $S$. aureus ocorreu em 23,3\% das amostras, o que evidencia novamente sua importância, por ser de grande ocorrência nos rebanhos analisados, e de tratamento difícil devido a elevada resistência aos antibióticos.

Verificou-se que todos os isolados de E. coli foram sensíveis à ampicilina (Tabela 3). Entretanto, os isolados de S. aureus, principal bactéria causadora de mastite bovina, apresentaram maior resistência frente aos antibióticos testados comparado aos isolados de E. coli. Isso evidencia a seleção desta bactéria ao longo do tempo devido à forte pressão seletiva imposta a mesma devido ao uso indiscriminado de antibióticos no tratamento de mastite.

De acordo com os resultados de Guimarães et al. (2012), os isolados de $S$. aureus obtidos a partir de amostras bovina apresentaram sensibilidade de $66,7 \%$ para tetraciclina e ampicilina, valores próximos aos encontrados no presente trabalho. Entretanto, Salaberry et al. (2013) ao comparar a resistência de estafilococos coagulase positiva frente a antibióticos, relatou maior resistência para tetraciclina, ressaltando novamente a seleção de bactérias resistentes, além da presença de resíduos no leite mastítico que pode gerar consequências graves ao consumidor.

A ampicilina apresenta grande eficácia contra microrganismos Gram positivos e Gram negativos. Esse antimicrobiano possui seu mecanismo de ação baseado na inibição da síntese da parede celular dos microrganismos. Os antibióticos tetraciclina e ácido nalidixico atuam na síntese de proteínas e sobre a enzima DNA girase, respectivamente, sendo, portanto, inibidores de bactérias Gram-positivas e Gramnegativas. Entretanto, neste estudo constatouse elevado percentual de isolados resistentes a estes antibióticos, sendo a maioria dos isolados de $E$. coli resistentes a tetraciclina e a maioria dos isolados de $S$. aureus resistentes ao ácido nalidixico (Tabela 3 ).

Constatou-se também neste estudo que todos os isolados de E. coli foram resistentes ao extrato bruto de aroeira-da-praia. Os isolados de $S$. aureus apresentaram em média halo de inibição de 13,15 mm (Tabela 4), o que demonstra o potencial de utilização deste extrato no controle de mastite bovina.

Segundo os critérios relatados por Cimanga et al. (2002), as zonas de inibição ao redor do disco de papel são classificadas de acordo com o tamanho dos halos encontrados no meio de cultura, sendo $>$ ou $=15 \mathrm{~mm}$ (forte inibição), < $15 \mathrm{~mm}$ (inibição moderada) e $<10 \mathrm{~mm}$ (inativo). Assim, constatou-se que o extrato de aroeira apresentou inibição moderada contra os isolados de $S$. aureus.

Tabela 3 - Sensibilidade das bactérias frente aos antibióticos rotineiramente utilizados na propriedade

\begin{tabular}{lcr}
\hline \multicolumn{1}{c}{ Antibióticos } & S. aureus & \multicolumn{1}{c}{ E. coli } \\
\hline Ampicilina $(10 \mu \mathrm{g})$ & $53,33 \%$ & $100,00 \%$ \\
Tetraciclina $(30 \mu \mathrm{g})$ & $66,66 \%$ & $25,00 \%$ \\
Ácido nalidixico $(30 \mu \mathrm{g})$ & $26,66 \%$ & $71,15 \%$ \\
\hline
\end{tabular}


Dessa forma, esse extrato torna-se assim, uma forma alternativa de controle deste patógeno por ser um antimicrobiano natural. No entanto, são necessários mais estudos para purificação de seu principio ativo e desenvolvimento de medicamentos contra a mastite bovina.

Tabela 4 - Inibição (halos em $\mathrm{mm}$ ) dos isolados de $S$. aureus pelo extrato de aroeirada-praia

\begin{tabular}{cc}
\hline Isolado & $\begin{array}{c}\text { Média dos halos de } \\
\text { inibição }(\mathrm{mm})\end{array}$ \\
\hline A9 & 14,00 \\
A9 & 11,33 \\
A12 & 15,33 \\
A12 & 13,00 \\
A12 & 11,33 \\
A22 1 & 12,66 \\
A22 2 & 13,66 \\
A26 & 10,33 \\
A38 1 & 12,33 \\
A38 2 & 13,33 \\
A39 & 12,33 \\
A40 & 21,33 \\
A45 1 & 12,00 \\
A45 2 & 12,66 \\
A45 3 & 11,66 \\
Média & 13,15 \\
\hline
\end{tabular}

\section{CONCLUSÕES}

As amostras de leite cru coletadas no rebanho leiteiro analisado apresentaram elevadas contagens de microrganismos do grupo coliformes, evidenciando a carência de adoção de Boas Práticas Agropecuárias na produção do leite.

Todos os isolados de E. coli foram sensíveis à ampicilina. Os isolados de $S$. aureus, principal bactéria causadora de mastite bovina, apresentam maior resistência frente aos antibióticos testados (ampicilina, tetraciclina e ácido nalidíxico) comparado aos isolados de E. coli.
O extrato bruto de aroeira apresenta inibição moderada sobre os isolados de S. aureus. Portanto, é uma alternativa complementar de controle deste patógeno, por ser um antimicrobiano natural, sendo necessários mais estudos para purificação de seu principio ativo e desenvolvimento de medicamentos contra a mastite bovina.

\section{AGRADECIMENTOS}

A equipe agradece ao Grupo PET Ciências Agrárias e a Fundação de Amparo à Pesquisa de Minas Gerais pelo apoio financeiro e ao Conselho Nacional de Desenvolvimento Científico e Tecnológico (CNPq) pela bolsa de iniciação científica concedida para a execução desta pesquisa.

\section{REFERÊNCIAS}

BORGES, A.C. et al. Microbiologia geral

- Práticas de laboratório. 2. ed. Viçosa: Universidade Federal de Viçosa, 2004. 72p.

BRASIL. Ministério da Agricultura, Pecuária e Abastecimento. Departamento de Inspeção de Produtos de Origem Animal. Instrução Normativa $n^{\circ} 62$, de 26 de agosto de 2003. Oficializa os métodos analíticos oficiais para análises microbiológicas para controle de produtos de origem animal e água. Diário Oficial da República Federativa do Brasil, Brasília, 18 set. 2003. Seção 1, p. 14.

CASSOL, D.M.S. et al. Mastite bovina. A Hora Veterinária, v.29, n.175, p.27-31, 2010.

CIMANGA, K. et al. Correlation between chemical composition and antibacterial activity of essential oils of some aromatic medicinal plants growing in the Democratic Republic of Congo. Journal of Ethnopharmacology, v.79, n.2, p.213-220, 2002. 
COSTA, E.M.M.B. et al. Estudo in vitro da ação antimicrobiana de extratos de plantas contra Enterococcus faecalis. Jornal Brasileiro de Patologia e Medicina Laboratorial, v.46, n.3, p.175-180, 2010.

DOWNES, F.P.; ITO, K.(Ed.) Compendium of methods for the microbiological examination of foods. 4.ed. Washington: American Public Health Association, 2001, $676 \mathrm{p}$.

GUIMARÃES, G. et al. Caracterização fenotípica, produção de biofilme e resistência aos antimicrobianos em isolados de Staphylococcus spp.obtidos de casos de mastite em bovinos e bubalinos. Pesquisa Veterinária Brasileira, v.32, n. 12, p.12191224, 2012.

KORNACKI, J.L.; JOHNSON, J.L. Enterobacteriaceae, coliforms, and Escherichia coli as quality and safety indicators. In: DOWNES, F.P; ITO, K. (Ed.). Compendium of methods for the microbiological examination of foods. 4.ed. Washington: American Public Health Association, 2001. p.69-82.

MARTINS, R.P. et al. Prevalência e etiologia infecciosa da mastite bovina na microrregião de Cuiabá, MT. Ciência Animal Brasileira, v.11, n.1, p.181-187, 2010.
NÓBREGA, D.B. et al. Utilização de composto homeopático no tratamento da mastite bovina. Arquivo Instituto de Biociências, v.76, n.4, p.523-537, 2009.

PEREIRA, A.V. et al. Efeitos antimicrobianos e genéticos de extratos vegetais sobre plasmídeos de resistência a antibióticos em microrganismos de origem bovina. Revista de Biologia e Farmácia, v.4, n.1, p.26-30, 2010.

SALABERRY, S.R.S. et al. Sensibilidade antimicrobiana dos Staphylococcus spp. isolados de mastite subclínica caprina. In: CONGRESSO BRASILEIRO DE QUALIDADE DO LEITE DO CONSELHO BRASILEIRO DE QUALIDADE DO LEITE, 05., 2013, Botucatu. Anais... Botucatu: FMVZ., 2013. p.30-31.

SANTOS, M.V.; TOMAZI, T. Vacinas e vacinações: uso de vacinas como ferramenta para controle da mastite bovina. Leite integral, v.06, n.38, p.20-27, 2012.

SILVA, L.R.; MAGALHÃES, M.C.; TEIXEIRA, N.M. Avaliação do efeito antimicrobiano de extratos vegetais, própolis e preparações homeopáticas em estirpes de Staphylococcus aureus isoladas de leite cru granelizado. 2010. 33p. Trabalho de conclusão de Curso (Departamento de Ciência e Tecnologia de Alimentos) - IF Sudeste MG, Campus Rio Pomba, Rio Pomba, 2010. 